\title{
Les majorités fragiles et l'éducation, Marie Mc Andrew
}

Presses de l'Université de Montréal/Montréal, 2010

\section{Pierre-Louis Gauthier}

\section{(2) OpenEdition}

\section{Journals}

Édition électronique

URL : http://journals.openedition.org/ries/2150

DOI : $10.4000 /$ ries. 2150

ISSN : 2261-4265

Éditeur

Centre international d'études pédagogiques

Édition imprimée

Date de publication : 1 décembre 2011

Pagination : 33-35

ISBN : 978-2-85420-593-0

ISSN : 1254-4590

Référence électronique

Pierre-Louis Gauthier, «Les majorités fragiles et l'éducation, Marie Mc Andrew », Revue internationale d'éducation de Sèvres [En ligne], 58 | décembre 2011, mis en ligne le 01 décembre 2011, consulté le 22 septembre 2020. URL : http://journals.openedition.org/ries/2150 ; DOI : https://doi.org/10.4000/ries 2150

Ce document a été généré automatiquement le 22 septembre 2020

(c) Tous droits réservés 


\section{Les majorités fragiles et l'éducation, Marie Mc Andrew}

Presses de l'Université de Montréal/Montréal, 2010

Pierre-Louis Gauthier

\section{RÉFÉRENCE}

Les majorités fragiles et l'éducation, Marie Mc Andrew, Presses de l'Université de Montréal/Montréal, 2010, 289 p.

1 On connaît les travaux de Marie McAndrew sur le multiculturalisme. Cette professeure de l'université de Montréal consacre son nouvel opus aux face à face communautaires, dans quatre régions où l'on trouve une communauté minoritaire dans son pays, face à "l'autre", mais majoritaire sur son territoire propre. Majoritaire donc, mais d'une majorité fragile dans l'assemblage national.

2 La scolarisation est le révélateur de cette coexistence pas toujours paisible au sein de sociétés divisées par l'histoire, la religion, la langue. L'ouvrage a pour mérite d'illustrer les dilemmes qui se posent à toute politique linguistique dans un contexte évolutif que d'aucuns considèrent comme menaçant. La survie identitaire est-elle compatible avec l'égalité des chances? Les objectifs culturels peuvent-ils s'accommoder des objectifs sociaux? Peut-on concilier la complétude institutionnelle et le respect communautaire?

3 L'auteur rappelle le processus historique qui a conduit à des situations séparées en matière d'éducation, l'ampleur de cette séparation, l'état actuel de la question sous l'impact du multiculturalisme et de l'immigration. L'équilibre linguistique qui avait été maintenu bon an mal an se trouve rompu, les immigrants recherchant plus un essor social qu'une identité nationale ou régionale.

4 Au Québec, la majorité francophone avait fait des écoles franco-catholiques le lieu d'un héritage de la culture canadienne française. Les progrès de l'immigration, plutôt portée vers les écoles anglo-protestantes, l'a fragilisée. Avec la Loi 101, rendant obligatoire 
l'enseignement du français pour les nouveaux arrivants, les écoles francophones ont perdu leur caractère de sanctuaire ethnique, pour devenir des milieux propices au multiculturalisme et au bilinguisme. Le caractère religieux des écoles francocatholiques a dû s'atténuer pour mieux capter le choix des nouveaux arrivants. La séparation reste souvent le fait des enseignants francophones dont $82 \%$ reconnaissent n'avoir jamais de contact avec leurs collègues anglophones.

5 La situation scolaire de la Belgique résulte de l'évolution politique et des relations conflictuelles entre Flandre et Wallonie, qui ont mené le pays au bord de la sécession. Les récentes évolutions socio-économiques ont exacerbé les différences. Partie d'une position majoritaire et dominante sur l'ensemble du royaume dès sa création (1832), la langue française a peu à peu régressé avec l'adoption du droit du sol en matière scolaire. Les conflits des années soixante ont étendu le principe du monolinguisme. Ce "nettoyage linguistique " a pour conséquence une situation de séparation à tous les niveaux d'enseignement. L'absence de contact est quasi-totale et il n'y a pas, en Belgique, d'université bilingue. Dans les deux régions, l'école est devenue une fabrique à stéréotypes qui compromet l'identité belge.

6 La situation scolaire de l'Irlande du Nord présente le cas de figure d'une langue majoritaire, l'anglais, porteur du protestantisme, imposée par la Direct Rule britannique à un territoire de tradition irlandaise et catholique. Le partage, pendant plus d'un demi-siècle, entre les écoles "controlled » publiques fréquentées par les protestants et les écoles «maintained» financées par l'église catholique n'excluait pas une certaine intégration. Les troubles tragiques des années soixante ont scellé la séparation. Paradoxalement, l'accord de paix ne l'a pas diminuée. L'effet minoritaire joue maintenant en faveur des écoles catholiques, qui se présentent comme les garantes de la langue irlandaise en préconisant le bilinguisme. Parmi les forces politiques, seul le Sin Féin préconise la réunification du système scolaire dans une Irlande réunifiée sur le modèle républicain français. Comme en Belgique, les responsables entretiennent les stéréotypes défensifs.

7 La Catalogne offre un cas d'école différent puisque son modèle scolaire, non confessionnel, prévoit l'unification linguistique et une scolarisation commune autour de la maîtrise des deux langues. Ce modèle s'est imposé en réaction aux années d'oppression du franquisme, qui préconisait système commun et langue unique avec le castillan. La majorité catalane ( $96 \%$ des élèves du primaire) contrôle l'éducatif, mais la montée du bilinguisme révèle sa relative fragilité. De fait, le castillan reste souvent la lingua franca dans les échanges entre jeunes. Sur cet aspect des échanges, l'auteur développe la théorie des contacts et des impacts d'identités supérieures aux communautés, à l'origine de la déconstruction des stéréotypes.

8 Le rôle de l'histoire, important depuis longtemps dans les systèmes d'éducation majoritaires, émerge maintenant dans des groupes ethniques qui peuvent se poser en victimes du colonialisme, de l'esclavage. Le «vivre ensemble» suppose une reconnaissance d'une autre lecture de l'histoire. Les majorités l'assument-elles au risque de se fragiliser? En Irlande du Nord, comment faire la place, dans l'enseignement de l'histoire longtemps limité à celle de la Grande-Bretagne, aux relations conflictuelles au long des derniers siècles, à la guerre civile? En Belgique, l'absence de tout rapprochement des interprétations historiques marque dramatiquement la rupture entre les deux communautés. L'auteur parle de schizophrénie. Le discours historique catalan réfute le courant identitaire de l'histoire 
téléologique " de Madrid », présentant la continuité espagnole de l'antiquité à l'époque moderne et traitant le fait régional comme un facteur d'anarchie qui justifiait un État autoritaire en 1936. La Catalogne s'oriente vers une histoire thématique de la Generalitat et des perspectives pluriculturelles et internationales.

9 La solution semble en effet de délimiter les thèmes qui permettent d'ordonner une remise en ordre du continuum historique : diversité, justice sociale, démocratie, droits de la personne.

10 Quelques remarques : on peut s'interroger sur le choix de territoires qui ont des statuts politiques différents : un État souverain (la Belgique) et trois régions dépendantes : une «nation» britannique (l'Irlande du Nord), une province canadienne (Québec), une région autonome (Catalogne), dont les compétences et les niveaux de décision politique ne sont pas toujours comparables. Enfin, l'immigration peut être interne et comporter les mêmes items culturels et linguistiques que l'immigration internationale (cas de l'immigration andalouse en Catalogne). La « défavorisation » scolaire, comme on dit au Québec, n'est pas seulement d'origine ethnique, mais surtout sociale, l'une renforçant souvent l'autre.

11 On comprendra le caractère tonique de cet ouvrage qui aborde sans fard les problèmes sensibles de systèmes éducatifs tiraillés entre repli et défense identitaires et ouverture à la diversité. L'ouvrage de Marie McAndrew marque sans aucun doute d'un repère capital le champ de la recherche universitaire sur le statut des systèmes scolaires minoritaires, ne serait-ce qu'en balisant des domaines peu ou pas étudiés.

\section{INDEX}

Index géographique : Catalogne, Belgique, Québec, Canada, Irlande du Nord

\section{AUTEURS}

\section{PIERRE-LOUIS GAUTHIER}

A été inspecteur d'académie, professeur d'histoire-géographie, inspecteur de l'éducation nationale, directeur d'école normale, directeur adjoint d'IUFM. Il est membre du comité de rédaction de la Revue internationale d'éducation de Sèvres depuis 1994. 